\title{
The boy whose arm wouldn't work
}

Patrick Keating, MD, and Alexander M. Getz, MD

\section{How would you handle this case?}

Answer the challenge questions at MDedge.com/ psychiatry and see how your colleagues responded

\section{f}

Discuss this article at www.facebook.com/ MDedgePsychiatry $\mathbf{Q}$

\section{CASE Drooling, unsteady, and not himself}

B, age 10, develops an unsteady gait and sustained flexion of his wrist. He has autism spectrum disorder and has maintained the same medication regimen for the last year. How do you proceed?

$B$, age 10 , who is left handed and has autism spectrum disorder, is brought to the emergency department (ED) with a 1-day history of drooling, unsteady gait, and left wrist in sustained flexion. His parents report that for the past week, B has had cold symptoms, including rhinorrhea, a low-grade fever $\left(100.0^{\circ} \mathrm{F}\right)$, and cough. Earlier in the day, he was seen at his pediatrician's office, where he was diagnosed with an acute respiratory infection and started on amoxicillin, $500 \mathrm{mg}$ twice daily for 7 days.

At baseline, $B$ is nonverbal. He requires some assistance with his activities of daily living. He usually is able to walk without assistance and dress himself, but he is not toilet trained. His parents report that in the past day, he has had significant difficulties with tasks involving his left hand. Normally, $B$ is able to feed himself "finger foods" but has been unable to do so today. His parents say that he has been unsteady on his feet, and has been "falling forward" when he tries to walk.

Two years ago, B was started on risperidone, $0.5 \mathrm{mg}$ nightly, for behavioral aggression and self-mutilation. Over the next 12 months, the dosage was steadily increased to $1 \mathrm{mg}$ twice daily, with good response. He has been taking his current dosage, $1 \mathrm{mg}$ twice daily, for the past 12 months without adjustment. His parents report there have been no other medication changes, other than starting amoxicillin earlier that day.

As part of his initial ED evaluation, $B$ is found to be mildly dehydrated, with an elevated sedimentation rate on urinalysis. His complete blood count (CBC) with differential is within normal limits. A comprehensive metabolic panel shows a slight increase in his creatinine level, indicating dehydration. $B$ is administered IV fluid replacement because he is having difficulty drinking due to excessive drooling.

The ED physician is concerned that B may be experiencing an acute dystonic reaction from risperidone, so the team holds this medication, and gives $B$ a one-time dose of IV diphenhydramine, $25 \mathrm{mg}$, for presumptive acute dystonic reaction. After several minutes, there is no improvement in the sustained flexion of his left wrist.

Dr. Keating is an Assistant Professor of Child and Adolescent Psychiatry, Department of Psychiatry, Broadlawns Medical Center - UnityPoint Health Des Moines, Des Moines, lowa. Dr. Getz is Child and Adolescent Psychiatry Assistant Program Director, Department of Neuropsychiatry, University South Carolina, Columbia, South Carolina.

Disclosures

The authors report no financial relationships with any companies whose products are mentioned in this article, or with manufacturers of competing products.

doi: $10.12788 /$ cp.0053 
Which laboratory and/or imaging tests should be considered for $B$ ?
a) MRI of brain with and without contrast
b) CT of neck and soft tissue
c) creatine phosphokinase (CPK) level
d) MRI of spine
e) All of the above

\section{The authors' observations}

B presented with new-onset neurologic findings after a recently diagnosed upper respiratory viral illness. His symptoms appeared to be confined to his left upper extremity, specifically demonstrating left arm extension at the elbow with flexion of the left wrist. He also had new-onset unsteady gait with a stooped forward posture and required assistance with walking. Interestingly, despite B's history of antipsychotic use, administering an anticholinergic agent did not lessen the dystonic posturing at his wrist and elbow.

\section{EVALUATION Laboratory results reveal new clues}

While in the ED, $B$ undergoes MRI of the brain and spinal cord to rule out any mass lesions that could be impinging upon the motor pathways. Both brain and spinal cord imaging appear to be essentially normal, without evidence of impingement of the spinal nerves or lesions involving the brainstem or cerebellum.

Due to concerns of possible airway obstruction, a CT scan of the neck is obtained to rule out any acute pathology, such as epiglottitis compromising his airway. The scan shows some inflammation and edema in the soft tissues that is thought to be secondary to his acute viral illness. $B$ is able to maintain his airway and oxygenation, so intubation is not necessary.

A CPK test is ordered because there are concerns of sustained muscle contraction of B's left wrist and elbow. The CPK level is $884 \mathrm{U} / \mathrm{L}$ (reference range 26 to $192 \mathrm{U} / \mathrm{L}$ ). The elevation in CPK is consistent with prior laboratory findings of dehydration and indicating skeletal muscle breakdown from sustained muscle contraction. All other laboratory results, including a comprehensive metabolic panel, urine drug screen, and thyroid screening panel, are within normal limits.

Which of the following should be considered in the differential diagnosis for $B$ ?
a) acute dystonic reaction
b) neuroleptic malignant syndrome
c) tardive dystonia
d) juvenile amyotrophic lateral sclerosis (ALS)
e) iatrogenic parkinsonism

\section{EVALUATION No variation in facial expression}

$B$ is admitted to the general pediatrics service. Maintenance IV fluids are started due to concerns of dehydration and possible rhabdomyolysis due to his elevated CPK level. Risperidone is held throughout the hospital course due to concerns for an acute dystonic reaction. B is monitored for several days without clinical improvement and eventually discharged home with a diagnosis of inflammatory mononeuropathy due to viral infection. The patient is told to discontinue risperidone as part of discharge instructions.

Five days later, B returns to the hospital because there was no improvement in his left extremity or walking. His left elbow remains extended with left wrist in flexion. Psychiatry is consulted for further diagnostic clarity and evaluation.

On physical examination, B's left arm remains unchanged. Despite discontinuing risperidone, there is evidence of cogwheel rigidity of the left wrist joint. Reflexes in the upper and lower extremities are $2+$ and symmetrical bilaterally, suggesting intact upper and lower motor pathways. Babinski sign is absent bilaterally, which is a normal finding in B's age group. B continues to have difficulty with ambulating and appears to "fall forward" while trying to walk with assistance. His par-

\section{Clinical Point}

Despite B's history of antipsychotic use, administering an anticholinergic agent did not lessen the dystonic posturing at his wrist and elbow 


\section{Clinical Point}

\section{Symptoms of tardive dyskinesia typically emerge after 1 to 2 years of continuous exposure to dopamine receptor blocking agents}

continued from page 55

\section{Table 1}

\section{Comparison of tardive dystonia vs acute dystonic reaction}

Tardive dystonia

\begin{tabular}{l}
\hline Gradual onset \\
$\begin{array}{l}\text { Average duration of DRBA therapy: Years } \\
\text { (average } 5.7 \text { years) }\end{array}$ \\
\hline Focal dystonia with segmental progression \\
\hline May improve but not resolve with anticholinergic \\
$\begin{array}{l}\text { Common forms: } \\
\text { - blepharospasm } \\
\text { - retrocollis } \\
\text { - truncal dystonia }\end{array}$ \\
\hline
\end{tabular}

Acute dystonic reaction Abrupt onset

Average duration of DRBA therapy: Hours to days

Focal only

Improves with DRBA removal and anticholinergic

Common forms:

- oromandibular dystonia

- blepharospasm

- oculogyric crisis

DRBA: dopamine receptor blocking agents

Source: Reference 2

ents also say that $B$ is not laughing, smiling, or showing any variation in facial expression.

Additional family history is gathered from B's parents for possible hereditary movement disorders such as Wilson's disease. They report that no family members have developed involuntary movements or other neurologic syndromes. Additional considerations on the differential diagnosis for B include juvenile ALS or mononeuropathy involving the $C 5$ and $C 6$ nerve roots. B's parents deny any recent shoulder trauma, and radiographic studies did not demonstrate any involvement of the nerve roots.

\section{TREATMENT A trial of bromocriptine}

At this point, B's neurologic workup is essentially normal, and he is given a provisional diagnosis of antipsychotic-induced tardive dystonia vs tardive parkinsonism. Risperidone continues to be held, and $B$ is monitored for clinical improvement. $B$ is administered a onetime dose of diphenhydramine, $25 \mathrm{mg}$, for dystonia with no improvement in symptoms. $\mathrm{He}$ is then started on bromocriptine, $1.25 \mathrm{mg}$ twice daily with meals, for parkinsonian symptoms secondary to antipsychotic medication use. After 1 day of treatment, B shows less sustained flexion of his left wrist. He is able to relax his left arm, shows improvements in ambulation, and requires less assistance. $B$ continues to be observed closely and continues to improve toward his baseline.

At Day 4, he is discharged. B is able to walk mostly without assistance and demonstrates improvement in left wrist flexion. He is scheduled to see a movement disorders specialist a week after discharge. The initial diagnosis given by the movement disorder specialist is tardive dystonia.

\section{The authors' observations}

Tardive dyskinesia is a well-known iatrogenic effect of antipsychotic medications that are commonly used to manage conditions such as schizophrenia or behavioral agitation associated with autism spectrum disorder. Symptoms of tardive dyskinesia typically emerge after 1 to 2 years of continuous exposure to dopamine receptor blocking agents (DRBAs). Tardive dyskinesia symptoms include involuntary, repetitive, purposeless movements of the tongue, jaw, lips, face, trunk, and upper and lower extremities, with significant functional impairment. ${ }^{1}$

Tardive syndromes refer to a diverse array of hyperkinetic, hypokinetic, and sensory movement disorders resulting from at least 3 months of continuous DRBA therapy. ${ }^{2}$ Tardive dyskinesia is perhaps the most well-known of the tardive syndromes, 


\section{AAN guidelines for the treatment of tardive dyskinesia}

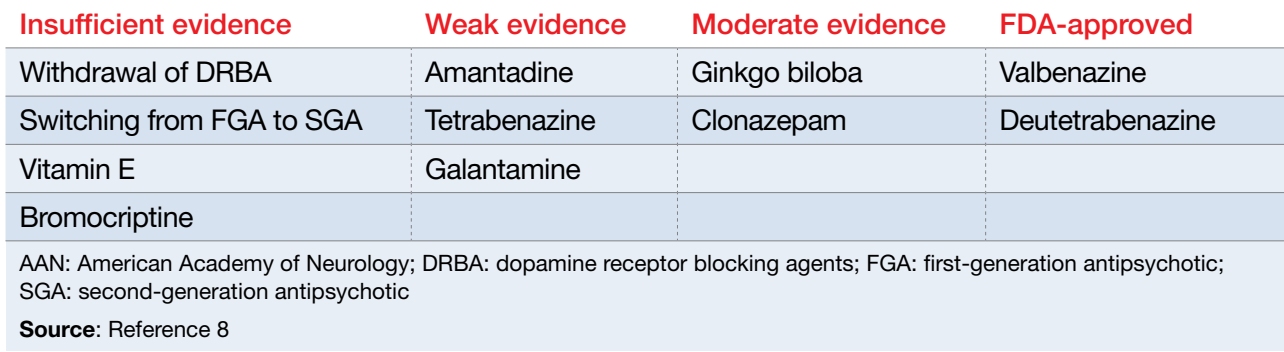

but is not the only one to consider when assessing for antipsychotic-induced movement disorders. A key feature differentiating a tardive syndrome is the persistence of the movement disorder after the DRBA is discontinued. In this case, B had been receiving a stable dose of risperidone for $>1$ year. He developed dystonic posturing of his left wrist and elbow that was both unresponsive to anticholinergic medication and persisted after risperidone was discontinued. The term "tardive" emphasizes the delay in development of abnormal involuntary movement symptoms after initiating antipsychotic medications. ${ }^{3}$ Table $\mathbf{1}^{2}$ (page 60) shows a comparison of tardive dystonia vs an acute dystonic reaction.

Other tardive syndromes include:

- tardive tics

- tardive parkinsonism

- tardive pain

- tardive myoclonus

- tardive akathisia

- tardive tremors.

The incidence of tardive syndromes increases $5 \%$ annually for the first 5 years of treatment. At 10 years of treatment, the annual incidence is thought to be $49 \%$, and at 25 years of treatment, $68 \%{ }^{4}$ The predominant theory of the pathophysiology of tardive syndromes is that the chronic use of DRBAs causes a gradual hypersensitization of dopamine receptors. ${ }^{4}$ The diagnosis of a tardive syndrome is based on history of exposure to a DRBA as well as clinical observation of symptoms.

Compared with classic tardive dyskinesia, tardive dystonia is more common among younger patients. The mean age of onset of tardive dystonia is 40 , and it typically affects young males. ${ }^{5}$ Typical posturing observed in cases of tardive dystonia include extension of the arms and flexion at the wrists. ${ }^{6}$ In contrast to cases of primary dystonia, tardive dystonia is typically associated with stereotypies, akathisia, or other movement disorders. Anticholinergic agents, such as benztropine or trihexyphenidyl, may or may not alleviate symptoms of tardive dystonia but can worsen tardive dyskinesia, so careful delineation between the 2 syndromes is important. ${ }^{6}$

The American Psychiatric Association has issued guidelines on screening for involuntary movement syndromes by using the Abnormal Involuntary Movement Scale (AIMS). ${ }^{7}$ The current recommendations include assessment every 6 months for patients receiving first-generation antipsychotics, and every 12 months for those receiving second-generation antipsychotics. ${ }^{7}$ Prescribers should also carefully assess for any pre-existing involuntary movements before prescribing a DRBA. ${ }^{7}$

\section{Which of the following are FDA-approved} treatments for tardive dyskinesia?

a) gingko biloba

b) vitamin $\mathrm{E}$

\section{Clinical Point}

A key feature
differentiating a
tardive syndrome is
the persistence of the
movement disorder
after the DRBA is
discontinued




\section{In B's case, bromocriptine was used to counter the dopamine-blocking effects of risperidone and his parkinsonian features improved}

c) valbenazine and deutetrabenazine

d) bromocriptine and clonazepam

\section{The authors' observations}

In 2013, the American Academy of

\begin{tabular}{|c|c|c|}
\hline Clinical Point & $\begin{array}{l}\text { Amantadine } \cdot \text { Gocovri, } \\
\text { Symmetrel } \\
\text { Amoxicillin·Amoxil } \\
\text { Baclofen } \cdot \text { Kemstro, } \\
\text { Liroesal } \\
\text { Benztropine } \cdot \text { Cogentin } \\
\text { Bromocriptine } \cdot \text { Parlodel } \\
\text { Clonazepam } \cdot \text { Klonopin }\end{array}$ & $\begin{array}{l}\text { Deutetrabenazine } \cdot \text { Austedo } \\
\text { Galantamine } \cdot \text { Razadyne } \\
\text { Quetiapine } \cdot \text { Seroquel } \\
\text { Risperidone } \cdot \text { Risperdal } \\
\text { Tetrabenazine } \cdot \text { Xenazine } \\
\text { Trihexyphenidyl } \cdot \text { Artane, } \\
\text { Tremin } \\
\text { Valbenazine } \cdot \text { Ingrezza }\end{array}$ \\
\hline & & \\
\hline
\end{tabular}

\section{Related Resources}

- American Academy of Neurology. Summary of evidence-based guideline for clinicians: treatment of tardive syndromes. https:// www.aan.com/Guidelines/Home/GetGuidelineContent/613. Published 2013.

- Dystonia Medical Research Foundation. https://dystoniafoundation.org/.

Drug Brand Names Neurology (AAN) published guidelines on the treatment of tardive dyskinesia. According to these guidelines, at that time, the treatments with the most evidence supporting their use were clonazepam, ginkgo biloba, amantadine, and tetrabenazine. ${ }^{8}$ Other medications, including bromocriptine, baclofen, botulinum toxin, and vitamin E, did not show sufficient evidence to be recommended or refuted as treatment options. ${ }^{8}$ Botulinum toxin has long been utilized to treat focal and cervical dystonias, although there is no clear consensus on its role in treating tardive syndromes because of the conflicting results of prior studies. ${ }^{8}$
Table $2^{8}$ (page 61) outlines the AAN guidelines for treating tardive dyskinesia.

In 2017, valbenazine and deutetrabenazine became the first FDA-approved treatments for tardive dyskinesia in adults. Both medications block the vesicular monoamine transporter 2 (VMAT2) system, which results in decreased synaptic dopamine and dopamine receptor stimulation. Both VMAT2 inhibitor medications have a category level A supporting their use for treating tardive dyskinesia. ${ }^{8-10}$

Currently, there are no published treatment guidelines on pharmacologic management of tardive dystonia. In B's case, bromocriptine, a dopamine agonist, was used to counter the dopamine-blocking effects of risperidone on the nigrostriatal pathway and improve parkinsonian features of B's presentation, including bradykinesia, stooped forward posture, and masked facies. Bromocriptine was found to be effective in alleviating parkinsonian features; however, to date there is no evidence demonstrating its effectiveness in countering delayed dystonic effects of DRBAs.

\section{OUTCOME Improvement of dystonia symptoms}

One week after discharge, B is seen for a follow-up visit. He continues taking bromocriptine, $1.25 \mathrm{mg}$ twice daily, with meals after discharge. On examination, he has some evidence of tardive dystonia, including flexion of left wrist and posturing while ambulating. B's parkinsonian features, including stooped

\section{Bottom Line}

Tardive dystonia is a possible iatrogenic adverse effect for patients receiving long-term dopamine receptor blocking agent (DRBA) therapy. Tardive syndromes encompass delayed-onset movement disorders caused by long-term blockade of the dopamine receptor by antipsychotic agents. Tardive dystonia can be contrasted from acute dystonic reaction based on the time course of development as well as by the persistence of symptoms after DRBAs are withheld. 
forward posture, masked facies, and cogwheel rigidity of the left wrist muscle, have resolved. $B$ is now able to walk on his own without unsteadiness. Bromocriptine is discontinued after 1 month, and his symptoms of dystonia continue to improve.

Two months after hospitalization, B is started on quetiapine, $25 \mathrm{mg}$ twice daily, for behavioral aggression. Quetiapine is chosen because it has a lower dopamine receptor affinity compared with risperidone, and theoretically, quetiapine is associated with a lower risk of developing tardive symptoms. During the next 6 months, B is monitored closely for recurrence of tardive symptoms. Quetiapine is slowly titrated to $25 \mathrm{mg}$ in the morning, and $50 \mathrm{mg}$ at bedtime. His behavioral agitation improves significantly and he does not have a recurrence of tardive symptoms.
References

1. Margolese HC, Chouinard G, Kolivakis TT, et al. Tardive dyskinesia in the era of typical and atypical antipsychotics. Part 1: pathophysiology and mechanisms of induction. Can J Psychiatr. 2005;50(9):541-547.

2. Truong D, Frei K. Setting the record straight: the nosology of tardive syndromes. Parkinsonism Relat Disord. 2019;59: 146-150.

3. Cornett EM, Novitch M, Kaye AD, et al. Medicationinduced tardive dyskinesia: a review and update. Ochsner J. 2017;17(2):162-174

4. Schooler NR, Kane JM. Research diagnoses for tardive dyskinesia. Arch Gen Psychiatry. 1982;39(4):486-487.

5. Fahn S, Jankovic J, Hallett M. Principles and Practice of Movement Disorders. 2nd ed. Philadelphia, PA: Saunders; 2011:415-446.

6. Kang UJ, Burke RE, Fahn S. Natural history and treatment of tardive dystonia. Mov Disord. 1986;1(3):193-208.

7. Lehman AF, Lieberman JA, Dixon LB, et al. Practice guideline for the treatment of patients with schizophrenia second edition. Am J Psychiatry. 2004;161(suppl 2):1-56.

8. Bhidayasiri R, Fahn S, Weiner WJ, et al, Evidence-based guideline: treatment of tardive syndromes: report of the Guideline Development Subcommittee of the American Academy of Neurology. Neurology. 2013;81(5):463-469.

9. Ingrezza [package insert]. San Diego, CA: Neurocrine Biosciences, Inc.; 2020

10. Austedo [package insert]. North Wales, PA: Teva Pharmaceuticals; 2017

\section{Clinical Point}

B was started on quetiapine, which has a lower dopamine receptor affinity compared with risperidone
From the Editor

continued from page 15

we employ the circuits of our brain where wisdom putatively resides ${ }^{11}$ and which may develop further (via neuroplasticity) with the conduct of psychotherapy. ${ }^{12}$ Those brain circuits include:

- prefrontal cortex (for emotional regulation, decision-making, and value relativism)

- lateral prefrontal cortex (to facilitate calculated, reason-based decision-making)

- medial prefrontal cortex (for emotional valence and pro-social attitudes and behaviors).

However, being human, it is quite likely that our amygdala may "seep through" and color our judgment and decisions. But let us try to cast a vote that is not only good for the country but also good for our patients, many of whom may not even be able to vote. Election season is a time to make a positive difference in our patients' lives, not just ours. Let's hope our brains exploit this unique opportunity.

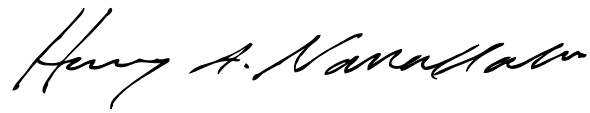

Henry A. Nasrallah, MD

Editor-in-Chief

\section{References}

1. Schreiber D. Neuropolitics: twenty years later. Politics Life Sci. 2017;36(2):114-131.

2. Sperry RW, Zaidel E, Zaidel D. Self recognition and social awareness in the deconnected minor hemisphere. Neuropsychologia. 1979;17(2):153-166

3. Knutson KM, Wood JN, Spampinato MV, et al. Politics on the brain: an FMRI investigation. Soc Neurosci. 2006;1(1): 25-40.

4. Oxley DR, Smith KB, Alford JR, et al. Political attitudes vary with physiological traits. Science. 2008;321(5896): 1667-1670.

5. Spezio ML, Rangel A, Alvarez RM, et al. A neural basis for the effect of candidate appearance on election outcomes. Soc Cogn Affect Neurosci. 2008;3(4): 344-352.

6. Zamboni G, Gozzi M, Krueger F, et al. Individualism, conservatism, and radicalism as criteria for processing political beliefs: a parametric fMRI study. Soc Neurosci. 2009;4(5):367-383.

7. Vecchiato G, Toppi J, Cincotti F, et al. Neuropolitics: EEG spectral maps related to a political vote based on the first impression of the candidate's face. Conf Proc IEEE Eng Med Biol Soc. 2010;2010:2902-2905.

8. Kanai R, Feilden T, Firth $\mathrm{C}$, et al. Political orientations are correlated with brain structure in young adults. Curr Biol. 2011;21(8):677-680.

9. Xia C, Stolle D, Gidengil E, et al. Lateral orbitofrontal cortex links social impressions to political choices. J Neurosci. 2015;35(22):8507-8514.

10. Bernabel RT, Oliveira A. Conservatism and liberalism predict performance in two nonideological cognitive tasks. Politics Life Sci. 2017;36(2):49-59.

11. Meeks TW, Jeste DV. Neurobiology of wisdom: a literature overview. Arch Gen Psychiatry. 2009;66(4):355-365.

12. Nasrallah HA. Does psychiatric practice make us wiser? Current Psychiatry. 2009;8(10):12,14
Election season is a time to make a positive difference in our patients' lives, not just ours 